\title{
Concentration Dependence of Antimicrobial Properties of Various Surfactants Against Bacteria Pseudomonas putida
}

\author{
Anastasiya S. Burlachenko and Olesya V. Salishcheva* \\ Kemerovo State University \\ Kemerovo, Russian Federation
}

Received 13.03.2021, received in revised form 03.05.2021, accepted 06.06.2021

\begin{abstract}
Effect of the concentration of surfactants differing in nature on the inhibition of the growth of microorganisms of the genus Pseudomonas putida was studied. All the surfactants inhibited the metabolic growth of microorganisms to various degrees. The results depended on the nature of the surfactants. For each surfactant, there is a range of concentrations characteristic of the growth or suppression of the growth of microorganisms. The values of the minimum inhibitory concentration and the growth inhibition zones diameters of the surfactants are compared. The highest antimicrobial activity belonged to the cationic Dimethylaminopropyl stearamide in relation to Pseudomonas putida.
\end{abstract}

Keywords: surfactants, antimicrobial properties, microorganisms, Pseudomonas putida.

Citation: Burlachenko A.S., Salishcheva O.V. Concentration dependence of antimicrobial properties of various surfactants against bacteria Pseudomonas putida, J. Sib. Fed. Univ. Chem., 2021, 14(2), 207-217. DOI: 10.17516/1998-2836-0229

(C) Siberian Federal University. All rights reserved

This work is licensed under a Creative Commons Attribution-NonCommercial 4.0 International License (CC BY-NC 4.0).

* Corresponding author E-mail address: salishchevaov@mail.ru 


\title{
Концентрационная зависимость противомикробных свойств \\ различных поверхностно-активных веществ \\ в отношении бактерий вида Pseudomonas putida
}

\author{
А.С. Бурлаченко, О.В. Салищева \\ Кемеровский государственный университет \\ Российская Федерация, Кемерово
}

\begin{abstract}
Аннотация. Изучено влияние концентрации поверхностно-активных веществ, различающихся природой, на подавление роста микроорганизмов рода Pseudomonas putida. Показано, что сурфактанты проявляют различные степени ингибирующего воздействия на рост тестируемых видов бактерий в зависимости от природы поверхностно-активных веществ. Для каждого сурфактанта существует собственный диапазон концентраций, отвечающий росту либо подавлению роста микроорганизмов. Сопоставлены значения минимальной ингибирующей концентрации и диаметров зон ингибирования роста исследованных веществ в отношении микроорганизмов. Высокую антимикробную активность против бактерий рода Pseudomonas putida показал катионактивный Dimethylaminopropyl stearamide.
\end{abstract}

Ключевые слова: поверхностно-активные вещества, антимикробные свойства, микроорганизмы, Pseudomonas putida.

Цитирование: Бурлаченко, А.С. Концентрационная зависимость противомикробных свойств различных поверхностноактивных веществ в отношении бактерий вида Pseudomonas putida / А. С. Бурлаченко, О. В. Салищева // Журн. Сиб. федер. ун-та. Химия, 2021, 14(2). С. 207-217. DOI: 10.17516/1998-2836-0229

\section{Введение}

Чрезвычайно распространенными соединениями являются поверхностно-активные вещества (ПАВ) - одна из важнейших групп органических соединений, обладающих дифильным строением и, следовательно, исключительной способностью значительно понижать свободную поверхностную энергию в результате адсорбции на поверхностях раздела различных фаз.

ПАВ можно классифицировать по различным признакам. По способности к диссоциации в водных растворах их подразделяют на неионогенные и ионогенные. В свою очередь ионогенные ПАВ делят на анионные, катионные, амфолитные и цвиттер-ионные [1].

Олеат натрия (sodium oleate) - представитель анионактивных ПАВ, используемый в качестве мицеллообразующего вещества [2, 3], эмульгатора, агента при флотации [4] (рис. 1).

Кокамидопропил бетаин (cocamidopropyl betain - CAPB) - цвиттер-ионный сурфактант, широко применяется для создания композиций в средствах для личной гигиены и косметических средств (рис. 2). САРВ является широко распространенным алкилбетаиновым ПАВ. Первым этапом синтеза служит реакция 3,3-диметиламинопропиламина с кокосовыми жирными кислотами $(\mathrm{R}=\mathrm{C} 7-\mathrm{C} 17)$, полученными при гидролизе кокосового масла, с образованием промежуточного кокамидопропил диметиламина. Данная реакция требует высоких температур 


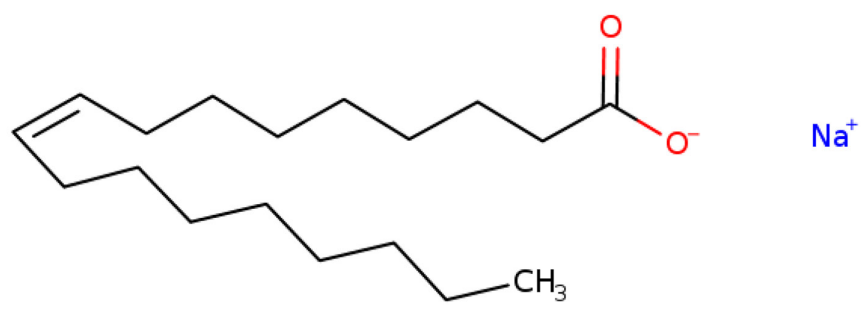

Рис. 1. Олеат натрия

Fig. 1. Sodium oleate

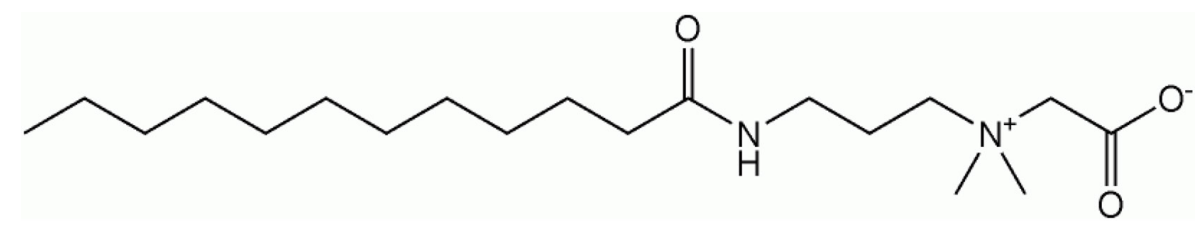

Рис. 2. Кокамидопропил бетаин

Fig. 2. Cocamidopropyl betain - CAPB

(150-175 $\left.{ }^{\circ} \mathrm{C}\right)$ для конверсии и последующей дистилляции, с целью удаления непрореагировавших исходных веществ. На втором этапе используют реакцию взаимодействия промежуточного продукта с монохлоруксусной кислотой.

Недавние исследования зарубежных ученых установили способность Cocamidopropyl Betaine к проявлению мощных антисептических свойств. При использовании искусственной вентиляции легких (ИВЛ) в лечении различных инфекционных заболеваний у пациентов образуются плотные и обильные слизистые выделения, закупоривающие эндотрахеальную трубку и затрудняющие ее аспирацию. Это обстоятельство вынуждает удалять трубку, очищать или заменять, увеличивая нагрузку на персонал, а также риск заражения. Сложившаяся санитарная ситуация способствовала разработке формулы поверхностно-активного вещества кокамидопропилбетаина в качестве $0,075 \%$-го раствора в физиологической сыворотке для гигиенического процесса интубации, который используется для предотвращения заражения [5].

Среди неионогенных ПАВ широко известны алкил глюкозиды, относящиеся к экологически чистым сурфактантам благодаря их полному биоразложению. Синтез проводят путем конденсации длинноцепочечных жирных спиртов кокосового или пальмового масла и глюкозы [6]. Алкил глюкозиды используют в косметологии [7], в промышленности и сельском хозяйстве их применяют в качестве эмульгаторов и солюбилизаторов [8]. Децил глюкозид (рис. 3) входит в состав косметических кремов, гелей и кондиционеров, являясь менее агрессивным компонентом, все же вызывающим аллергические реакции $[9,10]$. Описано применение неионных ПАВ в качестве нейтральных кислородсодержащих экстракционных реагентов [11].

Стеарамидопропил диметиламин (SAPDMA) широко используемое катионактивное ПАВ в составе кондиционеров для волос и средств личной гигиены (рис. 4). Однако, по данным PubChem и Европейского химического агентства, SAPDMA очень токсичен для водной среды с долгосрочными последствиями и может вызвать серьезные повреждения глаз и кожи [12].

$$
-209-
$$




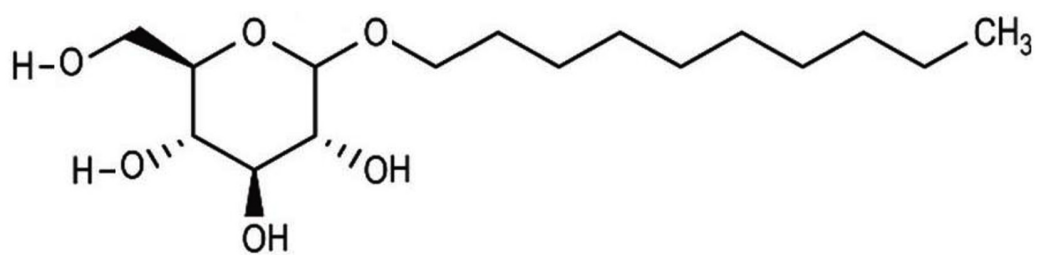

Рис. 3. Децил глюкозид

Fig. 3. Decyl glucoside

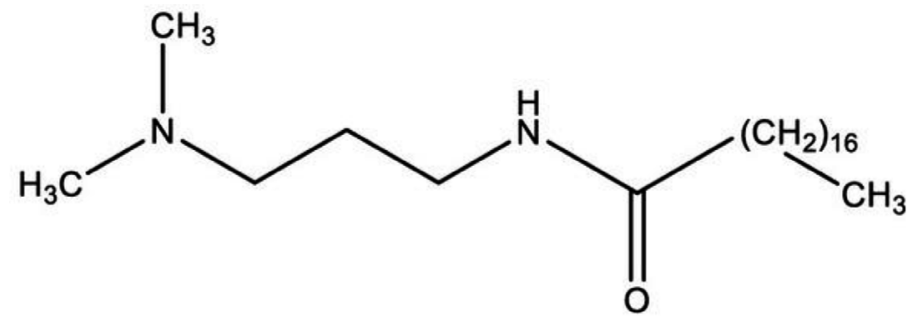

Рис. 4. Стеарамидопропил диметиламин

Fig. 4. Stearamidopropyl dimethylamine

Благодаря высокой поверхностной активности сурфактантов и образованию мицеллярных систем, приводящих к процессам адсорбции, адгезии, смачивания, солюбилизации, молекулы ПАВ способны проникать через биологические мембраны, нарушая физиологические процессы в клетке, тем самым проявляя ярко выраженные антимикробные свойства [13-15]. Токсичность ПАВ связана с их способностью взаимодействовать с компонентами цитоплазматической мембраны клеток живых организмов, вследствие чего мембрана перестает служить барьером проницаемости и ее деструкция с последующим проникновением поллютанта внутрь клетки и взаимодействием с клеточными белками, липидами и липопротеидами может привести к гибели клетки [16].

Целью исследований являлось изучение влияния концентрации сурфактантов на антимикробную активность по отношению к микроорганизмам рода Pseudomonas putida.

\section{Материалы и методы}

В качестве объектов для исследования были взяты сурфактанты, различающиеся по способности к диссоциации: цвиттер-ионный (цвиттер-ПАВ) - Cocamidopropyl betaine (CAPВ), анионактивный (АПАВ) - Sodium oleate, неионогенный (НПАВ) - Decyl Glucoside, катионактивный (КПАВ) - Dimethylaminopropyl stearamide (SAPDMA) (табл. 1).

В роли биодеструкторов использованы штаммы микроорганизмов Всероссийской коллекции ФГУП ГосНИИ Генетика (Москва) Pseudomonas putida ТП-19 (В-6582). Исследования выполнены в НИИ биотехнологии Кемеровского государственного университета.

Для штамма готовили суспензию на основе физиологического раствора $(0,9 \% \mathrm{NaCl})$ с конечной концентрацией $10^{7}-10^{8} \mathrm{KOЕ} /$ мл.

Микроорганизмы были культивированы при $37^{\circ} \mathrm{C}$ в жидкой питательной среде в соответствии с паспортом штамма с последующим инкубированием в течение 24-48 ч. Состав пи- 
Таблица 1. Характеристика объектов исследования

Table 1. Characterization of research objects

\begin{tabular}{|l|c|c|c|}
\hline \multicolumn{1}{|c|}{ Наименование } & Формула & Молекулярная масса & $\begin{array}{c}\text { Регистрационный } \\
\text { номер CAS }\end{array}$ \\
\hline $\begin{array}{l}\text { Кокамидопропил бетаин } \\
\text { (Сосатіdopropyl betaine) }\end{array}$ & $\mathrm{C}_{19} \mathrm{H}_{38} \mathrm{~N}_{2} \mathrm{O}_{3}$ & 342,28 & $61789-40-0$ \\
Олеат нитрия (Sodium oleate) & $\mathrm{C}_{18} \mathrm{H}_{33} \mathrm{O}_{2} \mathrm{Na}$ & 304,44 & $143-19-1$ \\
Децил глюкозид (Decyl Glucoside) & $\mathrm{C}_{16} \mathrm{H}_{32} \mathrm{O}_{6}$ & 320,42 & $58846-77-8$ \\
$\begin{array}{l}\text { Стеарамидопропил диметиламин } \\
\text { (Dimethylaminopropyl stearamide) }\end{array}$ & $\mathrm{C}_{23} \mathrm{H}_{48} \mathrm{~N}_{2} \mathrm{O}$ & 368,65 & $7651-02-7$ \\
\hline
\end{tabular}

тательной культуральной среды, г/л: пептон - 10, мясной экстракт - $11, \mathrm{NaCl}-5$, вода дистиллированная - 1 л.

Численность колоний определяли с помощью денситометра DEN-1 по мутности клеточных суспензий в пределах значения 0,5 единиц Мак-Фарланда ( $\left.1 \cdot 10^{8} \mathrm{KOE} / \mathrm{Mл}\right)$.

Концентрация, ингибирующая рост микроорганизмов, определена макрометодом путем двукратного разбавления водных растворов ПАВ в пробирках с последующим добавлением суспензии штамма-деструктора. Начальная концентрация ПАВ составляла 0,3-0,4 моль/дм³ $\left(125\right.$ г/дм $\left.{ }^{3}\right)$.

Рост микроорганизмов контролировали после инкубирования при $37{ }^{\circ} \mathrm{C}$ через 24 ч, измеряя светорассеяние при $\lambda=980$ нм с помощью спектрофотометра UV 1800 (Shimadzu) при толщине слоя 1 см. Минимальная ингибирующая концентрация (МИК) соответствует минимальному содержанию ПАВ в растворе, при котором происходит сдерживание видимого роста тест-культур.

Для тестирования антибактериальной активности использовали диск-диффузионный метод. На поверхность агаризованной среды вносили 1 мл суспензии исследуемых микроорганизмов (106-10 $0^{8} \mathrm{KOЕ/мЛ),} \mathrm{помещали} \mathrm{бумажные} \mathrm{диски,} \mathrm{пропитанные} \mathrm{концентрированным} \mathrm{(30-50} \mathrm{\% )}$ и разбавленным (10 \%) водными растворами сурфактанта. После культивирования при $37{ }^{\circ} \mathrm{C}$ в течение 48 ч наблюдали зоны ингибирования. Для сравнения был взят антибактериальный препарат, содержащий изопропиловый спирт (70 \% об.).

Эксперименты для каждого ПАВ проводили в двух параллелях в трех повторностях, данные представлены как среднее значение.

\section{Результаты и их обсуждение}

Диск-диффузионный эксперимент, проведенный с концентрированными растворами ПАВ, показал рост микроорганизмов на периферии чашки и полное подавление роста не только вокруг дисков, но и по всей зоне сегмента для каждого ПАВ (рис. 5). Это являлось прямым доказательством токсичности взятых для исследования сурфактантов по отношению к бактериям рода Pseudomonas putida. В результате проведенного аналогичного исследования с разбавленными растворами сурфактантов наблюдались характерные зоны ингибирования - области, где происходит подавление роста бактерий (рис. 6).

Результаты измерений зон ингибирования роста бактерий представлены в табл. 2.

$$
-211-
$$




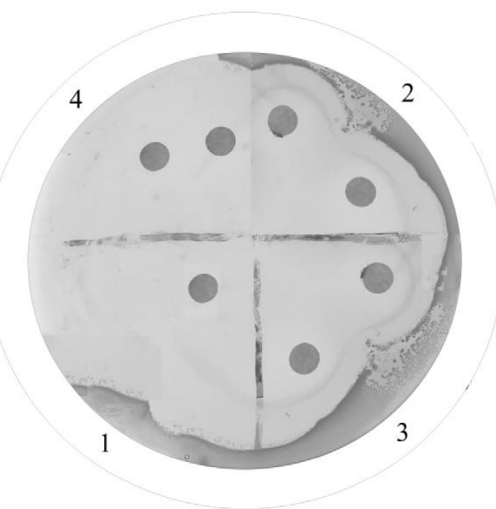

Рис. 5. Зоны ингибирования роста Pseudomonas putida под воздействием поверхностно-активных веществ: 1 - Cocamidopropyl betaine; 2 - Sodium oleate; 3 - Decyl glucoside; 4 - Dimethylaminopropyl stearamide

Fig. 5. Growth inhibition zones of the Pseudomonas putida under the influence of surfactant: 1 - Cocamidopropyl betaine; 2 - Sodium oleate; 3 - Decyl glucoside; 4 - Dimethylaminopropyl stearamide

1

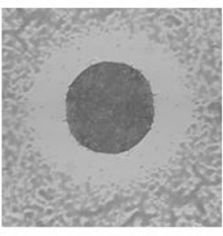

2

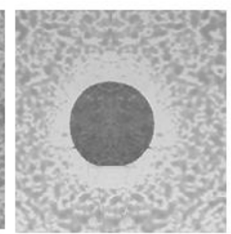

3

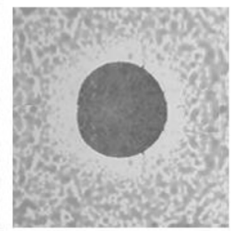

4

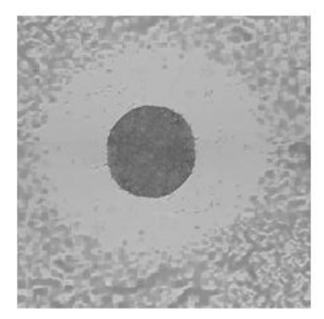

5

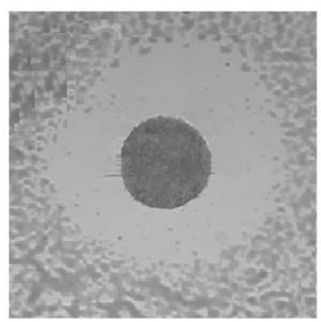

Рис. 6. Диаметр зоны ингибирования роста Pseudomonas putida под воздействием поверхностно-активных веществ: 1 - Cocamidopropyl betaine; 2 - Sodium oleate; 3 - Decyl glucoside; 4 - Dimethylaminopropyl stearamide; 5 - контроль (антибактериальный препарат)

Fig. 6. Growth inhibition zone diameter of the Pseudomonas putida under the influence of surfactant: 1 Cocamidopropyl betaine; 2 - Sodium oleate; 3 - Decyl glucoside; 4 - Dimethylaminopropyl stearamide; 5 control

Таблица 2. Диаметр зон ингибирования роста Pseudomonas putida под воздействием поверхностноактивных веществ

Table 2. Growth inhibition zones diameter of the Pseudomonas putida under the influence of surfactant

\begin{tabular}{|l|c|}
\hline \multicolumn{1}{|c|}{ ПАВ } & Диаметр зоны ингибирования, мм \\
\hline Кокамидопропил бетаин (Cocamidopropyl betaine) & $8 \pm 0,02$ \\
Олеат нитрия (Sodium oleate) & $9 \pm 0,02$ \\
Децил глюкозид (Decyl Glucoside) & $18 \pm 0,03$ \\
Стеарамидопропил диметиламин (Dimethylaminopropyl stearamide) & $20 \pm 0,08$ \\
Контроль - изопропиловый спирт & \\
\hline
\end{tabular}


Полученные данные показали, что максимальная зона ингибирования соответствует катионактивному ПАВ и контролю, обладающим самыми высокими бактерицидными свойствами. Наименьшая ингибирующая активность наблюдалась у анионактивного сурфактанта и у неоиногенного ПАВ. Несколько большую зону ингибирования по сравнению с НПАВ и АПАВ и меньшую, чем КПАВ, проявил цвиттер-ионный ПАВ. Эти результаты не противоречат имеющимся в литературе данным, в соответствии с которыми наиболее токсичны катионактивные ПАВ [1].

В работе [17] описан механизм токсичности для катионных ПАВ на основе алкилтриметиламмония, обнаруженный с помощью электронной микроскопии, который основан на сигналах флуоресценции в реальном времени и на изменении ультраструктуры клетки.

В процессе исследования решали вопрос подбора критической концентрации сурфактанта, при которой не происходит подавления жизнедеятельности микроорганизмов, поскольку имеются исследования, доказывающие способность некоторых штаммов использовать ПАВ в качестве питательного субстрата, что по сути и является процессами биодеструкции сурфактантов.

При подборе оптимальной концентрации сурфактанта с целью предотвращения ингибирующего действия на штаммы микроорганизмов необходимо было учитывать тот факт, что собственно сам ПАВ проявляет губительное действие в отношении микроорганизмов. Механизм антимикробной активности ПАВ связывают с адсорбцией ПАВ и образованием комплексов на поверхности микробной клетки, изменением электрохимических свойств и проницаемости мембраны и, как следствие, нарушением физиологических процессов и ферментативной активности микроорганизмов [18]. С другой стороны, многие микроорганизмы продуцируют биологически активные вещества - бактериоцины, обладающие широким антимикробным спектром [19-22].

Так, минимальные ингибирующие концентрации микробных ПАВ - липопептидов, синтезированных представителями родов Bacillus, Paenibacillus, Pseudomonas, Brevibacillus; рамнолипидов, синтезированных бактериями родов Pseudomonas, Burkholderia, Lysinibacillus; софоролипидов, синтезированных дрожжами родов Candida (Starmerella и Rhodotorula), - coставляют 1-32, 50-500 и 10-200 (мкг/мл) соответственно [23].

Активность микроорганизмов Pseudomonas putida по отношению к сурфактантам была подтверждена путем определения значений минимальной ингибирующей концентрации методом разведения в пробирке, при котором рост биомассы наблюдался лишь при низких концентрациях ПАВ.

Зависимость интенсивности светорассеяния от концентрации сурфактантов представлена на рис. 7.

Исследуемые микроорганизмы начали активный рост уже в первые сутки эксперимента без периода адаптации, используя в качестве единственного источника углерода только ПАВ. Это свидетельствует о том, что микроорганизмы рода Pseudomonas putida способны вызывать биодеградацию сурфактантов. Известно, что внесенные в систему углеводородов ПАВ играют существенную роль в процессах биоокисления, выполняя роль «посредников» между клеткой и ароматическими соединениями, способствуя адгезии клеток и гидрофобного субстрата и обеспечивая его транспорт внутрь клетки [24].

$$
-213-
$$



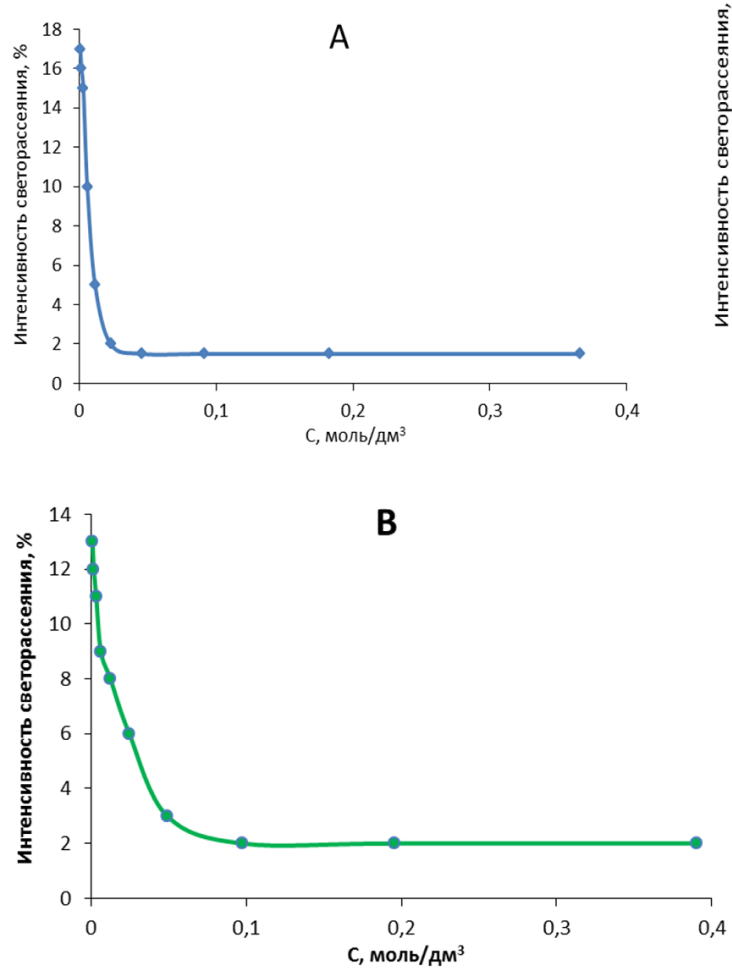
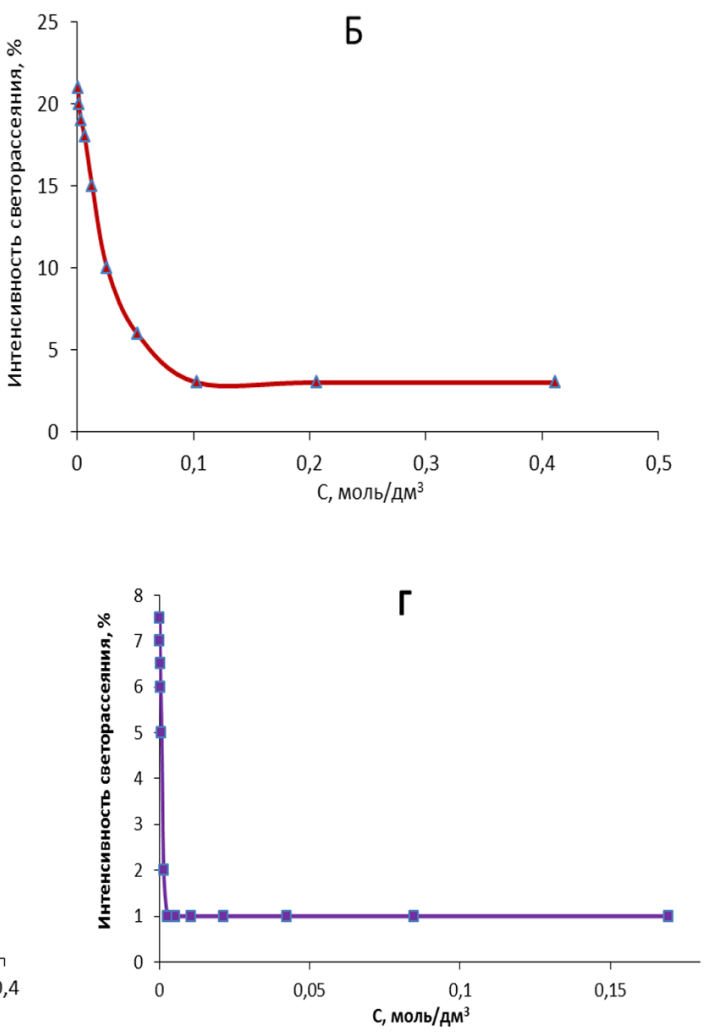

Рис. 7. Зависимость интенсивности рассеяния света от концентрации ПАВ: A - Cocamidopropyl betaine; Б - Sodium oleate; B - Decyl Glucoside; $\Gamma$ - Dimethylaminopropyl stearamide

Fig. 7. Dependence of the light scattering intensity on the surfactant concentration: A - Cocamidopropyl betaine; Б - Sodium oleate; B - Decyl Glucoside; $\Gamma$ - Dimethylaminopropyl stearamide

Сопоставление данных нефелометрических исследований подтвердило высокую токсичность катионактивного ПАВ (рис. 8), которая связана с высокой адсорбцией положительно заряженного поверхностно-активного катиона и отрицательно заряженной поверхности биологических мембран, что приводит к нарушению проницаемость последних и их разрушению $[16,18]$. Значение минимальной ингибирующей концентрации (МИК) для КПАВ превышает значение МИК для АПАВ более чем в 77 раз, для цвиттер-ионного ПАВ - в 17 раз, для НПАВ - 37 раз. Для цвиттер-ионного ПАВ и НПАВ получены практически схожие результаты, различающиеся в два раза. Самая высокая ингибирующая концентрация соответствует анионактивному ПАВ.

По численному значению интенсивности светорассеяния можно сделать следующие выводы. В среде, в которой в качестве источника углерода используется АПАВ, наблюдается активный прирост биомассы, что приводит к увеличению значения светорассеяния. В то же время при концентрации, меньшей МИК, малое значение интенсивности рассеяния света для КПАВ говорит об угнетении активного роста штамма. Возможно, это свидетельствует о том, что микроорганизмы могут использовать анионактивный ПАВ как легко усвояемый источник углерода, а катионактивный ПАВ не может являться полноценным субстратом, и клетка микроорганизма живет за счет своих внутренних резервов, которые быстро истощаются. 


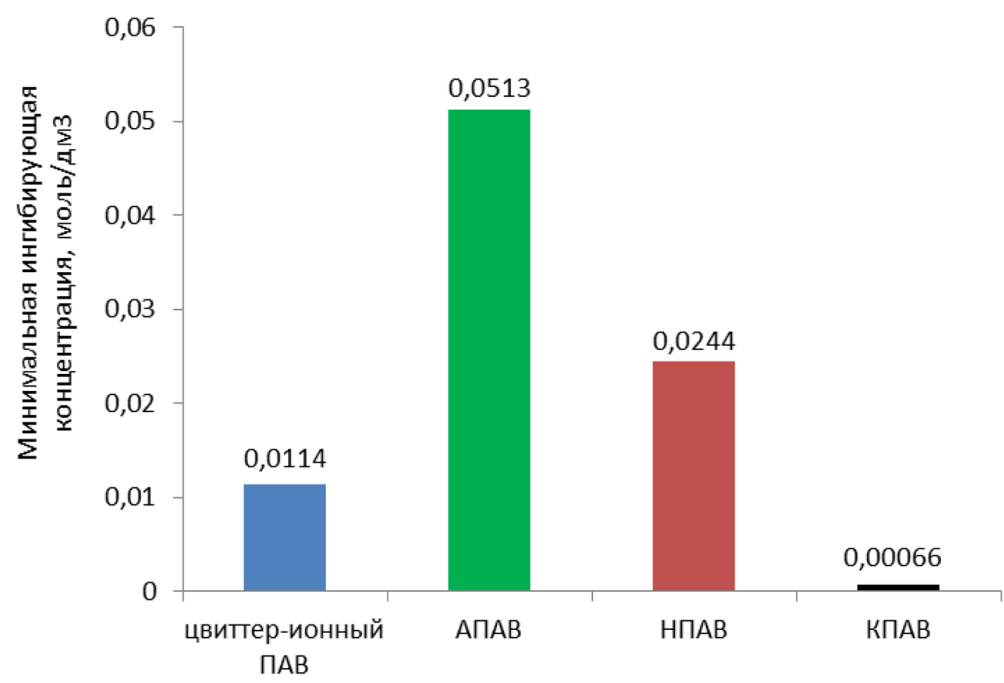

Рис. 8. Сравнение значений минимальной ингибирующей концентрации ПАВ в отношении микроорганизмов Pseudomonas putida

Fig. 8. Comparison of the values of the minimum inhibitory concentration of surfactants against Pseudomonas putida

\section{Заключение}

Таким образом, проведенные исследования доказали влияние концентрации ПАВ на жизнедеятельность микроорганизмов.

Показано, сурфактанты проявляют различные степени ингибирующего воздействия на рост тестируемых видов бактерий в зависимости от природы ПАВ. Для каждого сурфактанта существует собственный диапазон концентраций, отвечающий росту либо подавлению роста микроорганизмов. Высокую антимикробную активность против бактерий рода Pseudomonas putida имеет катионактивный ПАВ - Dimethylaminopropyl stearamide, показавший самое низкое значение минимальной ингибирующей концентрации.

При создании антисептических средств на основе ПАВ необходимо учитывать природу сурфактанта и значения концентрации, губительной для роста микроорганизмов.

\section{Список литературы / References}

1. Поверхностно-активные вещества и полимеры в водных растворах. Холмберг К., Йенссон Б., Кронберг Б., Линдман Б. Москва: Лаборатория знаний, 2020. 531 с. [Surfactants and polymers in aqueous solutions. Holmberg K., Jensson B., Kronberg B., Lindman B. Moscow.: Laboratory of Knowledge, 2020. 531 p. (In Russ.)].

2. Zou S., Wang Sh., Zhong H., Qin W. Hydrophobic agglomeration of rhodochrosite fines in aqueous suspensions with sodium oleate. Powder Technology 2021. Vol. 377, P. 186-193. DOI: https:// doi.org/10.1016/j.powtec.2020.08.019.

3. Tatini D., Raudino M., Ambrosi M., Carretti E., Davidovich I., Talmon Y., Ninham B.W., Lo Nostro P. Physicochemical characterization of green sodium oleate-based formulations. Part 1. Structure and rheology. Journal of Colloid and Interface Science 2021. Vol. 590, P. 238-248. DOI: https:// doi.org/10.1016/j.jcis.2021.01.040. 
4. Abaka-Wood G.B., Zanin M., Addai-Mensah J., Skinner W. The upgrading of rare earth oxides from iron-oxide silicate rich tailings: Flotation performance using sodium oleate and hydroxamic acid as collectors. Advanced Powder Technology 2018. Vol. 29(12), P. 3163-3172. DOI: https://doi. org/10.1016/j.apt.2018.08.019.

5. Nogales L.M., Jiménez L.L., Abarca L.E., Gil M.M., López-Nieves M. Cocamidopropyl Betaine Surfactant 0.075 \% Solution in Physiological Serum for Hygiene Process of COVID-19 Intubated Patients. International journal of pharmaceutical compounding 2020. Vol. 24(5), P. 358-364.

6. Thenchartanan P., Pitchayatanakorn Ph., Wattana-Amorn P., Ardá A., Svasti J., Jiménez-Barbero J., Kongsaeree P.T. Synthesis of long-chain alkyl glucosides via reverse hydrolysis reactions catalyzed by an engineered $\beta$-glucosidase. Enzyme and Microbial Technology 2020. Vol. 140, P. 109591. DOI: https://doi.org/10.1016/j.enzmictec.2020.109591.

7. Pajić N.B., Ilić T., Nikolić I., Dobričić V., Pantelić I., Savić S. Alkyl polyglucoside-based adapalene-loaded microemulsions for targeted dermal delivery: Structure, stability and comparative biopharmaceutical characterization with a conventional dosage form. Journal of Drug Delivery Science and Technology 2019. Vol. 54, P. 101245. DOI: https://doi.org/10.1016/j.jddst.2019.101245.

8. Cerón-Camacho R., Martínez-Palou R., Chávez-Gómez B., Cuéllar F., Bernal-Huicochea C., Clavel J.-C., Aburto J. Synergistic effect of alkyl-O-glucoside and -cellobioside biosurfactants as effective emulsifiers of crude oil in water. A proposal for the transport of heavy crude oil by pipeline. Fuel 2013. Vol. 110, P. 310-317. DOI: https://doi.org/10.1016/j.fuel.2012.11.023.

9. Boozalis E., Patel Sh. Allergen of the Year alkyl glucoside is an ingredient in top-selling sunscreens and facial moisturizers. Journal of the American Academy of Dermatology 2018. Vol. 78(4), P. 809-810. DOI: https://doi.org/10.1016/j.jaad.2017.10.013.

10. Fiume M.M., Heldreth B., Bergfeld W.F., Belsito D.V., Hill R.A., Klaassen C.D., Liebler D., Marks J.G.Jr., Shank R.C., Slaga T.J., Snyder P.W., Andersen F.A. Safety assessment of decyl glucoside and other alkyl glucosides as used in cosmetics. International Journal of Toxicology 2013. Vol. 32(5), P. 22S-48S. DOI: https://doi.org/10.1177/1091581813497764.

11. Stankova A.V., Elokhov A.M., Lesnov A.E. Halide and thiocyanate metal acid complexes extraction in the water - ethoxylated nonylphenol - ammonium sulfate system. Journal of Siberian Federal University. Chemistry 2019. Vol. 12(3), P. 328-335. DOI: 10.17516/1998-2836-0130.

12. Al-Jamal O., Al-Jighefee H., Younes N., Abdin R., Al-Asmakh M.A., Radwan A.B., Sliem M.H., Majdalawieh A.F., Pintus G., Yassine H.M., Abdullah A.M., Da'as S.I., Nasrallah G.K. Organ-specific toxicity evaluation of stearamidopropyl dimethylamine (SAPDMA) surfactant using zebrafish embryos. Science of The Total Environment 2020. Vol. 741, P. 140450. DOI: https://doi. org/10.1016/j.scitotenv.2020.140450.

13. Hamouda T., Myc A., Donovan B., Shih A.Y., Reuter J.D., Baker J.R. A novel surfactant nanoemulsion with a unique non-irritant topical antimicrobial activity against bacteria, enveloped viruses and fungi. Microbiological Research 2001. Vol. 156(1), P. 1-7. DOI: https://doi.org/10.1078/0944-501300069 .

14. Reijmar K., Schmidtchen A., Malmsten M. Bactericidal and hemolytic properties of mixed LL-37/surfactant systems. Journal of Drug Delivery Science and Technology 2007. Vol. 17(4), P. 293297. DOI: https://doi.org/10.1016/S1773-2247(07)50098-5. 
15. Salishcheva O.V., Prosekov A.Y. Antimicrobial activity of mono- and polynuclear platinum and palladium complexes. Foods and Raw Materials 2020. Vol. 8(2), P. 298-311. DOI: http://doi. org/10.21603/2308-4057-2020-2-298-311.

16. Domracheva L.I., Simakova V.S. Reactions of proand eukaryotic microorganisms to the action of synthetic surfactants (review). Theoretical and Applied Ecology 2018. Vol. 1, P. 5-17. DOI: 10.25750/1995- 4301-2018-1-005-017.

17. Wu X., Viner-Mozzini Y., Jia Y., Song L., Sukenik A. Alkyltrimethylammonium (ATMA) surfactants as cyanocides - Effects on photosynthesis and growth of cyanobacteria. Chemosphere 2021. Vol. 274, P. 129778. DOI: https://doi.org/10.1016/j.chemosphere.2021.129778.

18. Salishcheva O.V., Prosekov A.Yu., Dolganuk B.F. Antimicrobial activity of mononuclear and bionuclear nitrite complexes of platinum (II) and platinum (IV). Food Processing: Techniques and Technology 2020. Vol. 50(2), P. 329-342. DOI: https://doi.org/10.21603/2074-9414-2020-2-329-342.

19. Zimina M.I., Gazieva A.F., Pozo-Dengra J., Noskova S.Y., Prosekov A.Y. Determination of the intensity of bacteriocin production by strains of lactic acid bacteria and their effectiveness. Foods and Raw Materials 2017. Vol. 5(1), P. 108-117. DOI: http://doi.org/10.21179/2308-4057-2017-1-108-117.

20. Woraprayote W., Pumpuang L., Tosukhowong A., Roytrakul S., Perez R.H., Zendo T., Sonomoto K., Benjakul S., Visessanguan W. Two putatively novel bacteriocins active against Gramnegative food borne pathogens produced by Weissella hellenica BCC 7293. Food Control 2015. Vol. 55, P. 176-184. DOI: https://doi.org/10.1016/j.foodcont.2015.02.036.

21. Parret A.H., De Mot R. Bacteria killing their own kind: novel bacteriocins of Pseudomonas and other $\gamma$-proteobacteria. Trends in Microbiology 2002. Vol. 10(3), P. 107-112. DOI: https://doi. org/10.1016/S0966-842X(02)02307-7.

22. Sun D., Zhuo T., Hu X., Fan X., Zou H. Identification of a Pseudomonas putida as biocontrol agent for tomato bacterial wilt disease. Biological Control 2017. Vol. 114, P. 45-50. DOI: https://doi. org/10.1016/j.biocontrol.2017.07.015.

23. Pirog T.P., Lutsay D.A., Kliuchka L.V., Beregova K.A. Antimicrobial activity of surfactants of microbial origin. Biotechnologia Acta 2019. Vol. 12(1), P. 39-57. DOI: https://doi.org/10.15407/biotech12.01.039.

24. Karpenko E.V., Vil'danova-Martsishin R.I., Shcheglova N.S., Pirog T.P., Voloshina I.N. The Prospects of Using Bacteria of the Genus Rhodococcus and Microbial Surfactants for the Degradation of Oil Pollutants. Applied Biochemistry and Microbiology 2006. Vol. 42(2), P. 156-159. DOI: 10.1134/ S0003683806020074. 